\title{
A PRÁTICA PEDAGÓGICA DOS DIREITOS HUMANOS: MARCADORES SOCIAIS DA DIFERENÇA E O COMBATE AO BULLYING
}

\author{
Marcelo Henrique Goncalves de Miranda ${ }^{1}$ \\ Larissa Suellen Gomes Andrade de Lima ${ }^{2}$
}

\begin{abstract}
Resumo: O artigo propõe analisar a atividade de docentes de direitos humanos em escolas de Caruaru/PE na promoção de educação para os Direitos Humanos $(\mathrm{DH})$, no fortalecimento do combate ao racismo e à LGBTfobia via uma prática pedagógica antibullying. Utiliza-se a Análise de Conteúdo e as técnicas: conversas informais, observação e entrevistas semiestruturadas. O objetivo geral foi investigar como duas escolas de Referências do Ensino Médio promovem uma educação em e para os DH. Como resultado, compreende-se que os docentes promoviam timidamente uma prática pedagógica que problematizava as subalternidades interseccionais - os marcadores sociais da diferença. Entretanto, suas ações contra o bullying misógino, LGBT fóbico e racista nas escolas ainda é frágil e sem uma formação profissional tanto inicial como continuada. Assim, faz-se urgente uma profissionalização do professor do componente curricular de DH.
\end{abstract}

Palavras-chave: Educação, Interseccionalidade, Bullying.

\section{LA PRÁCTICA PEDAGÓGICA DE LOS DERECHOS HUMANOS: MARCADORES SOCIALES DE LA DIFERENCIA Y EL COMBATE AL BULLYING}

Resumen: El artículo propone analizar la actividad de docentes de derechos humanos en escuelas de Caruaru/PE en la promoción de la educación en y hacia los Derechos Humanos (DDHH), en el fortalecimiento de la lucha contra el racismo y la LGBTfobia a través de una práctica pedagógica antibullying. Se utiliza el Análisis de Contenido y las técnicas: conversaciones informales, observación y entrevistas semiestructuradas. El objetivo general fue investigar cómo dos escuelas de Referencias de la Enseñanza Media promueven una educación en y para los DDHH. Como resultado, se comprende que los docentes promovían tímidamente una práctica pedagógica que problematizaba las subalternidades interseccionales - los marcadores sociales de la diferencia. Sin embargo, sus acciones contra el bullying misógino, LGBTfóbico y racista en las escuelas todavía es frágil y sin una formación profesional tanto inicial y como continuada. Así, se hace urgente una profesionalización del profesor del componente curricular de DDHH.

Palabras clave: Educación, Interseccionalidad, Bullying.

\section{INTERSECCIONALIDADE, DIREITOS HUMANOS E COMBATE}

\section{AO BULLYING}

$\mathrm{Na}$ sociedade brasileira, de forma mais ampla, e no cotidiano escolar, de maneira específica, temos processos de inteligibilidade social que materializam discursos, opiniões, representações e práticas baseadas no que é considerado ser macho ou fêmea, ser homem ou ser mulher, ser heterossexual ou homossexual, ser branco ou ser afro-brasileiro, ser pobre ou ser rico. Tais marcadores sociais determinam socializações e sociabilidades que incluem ou excluem indivíduos e ou grupos na reprodução das subalternidades e desigualdades em nossa sociedade. Como exemplo

\footnotetext{
1 Graduação em Licenciatura em História - UNICAP; Mestrado em Sociologia e Doutorado em Sociologia pela UFPE.

${ }^{2}$ Graduanda em Licenciatura em Matemática - UFPE.
} 
dessas subalternidades em relação à sexualidade, podemos pensar que tais categorias dicotômicas, hierarquizadas e excludentes colocam a heterossexualidade como "normal", "natural" e, ainda, "sadia" e a homossexualidade como par inferior (BUTLER, 2003; MATTOS, 2011; MIRANDA, 2013).

Nessa perspectiva, em relação ao campo de produção de conhecimento acerca dos estudos das subalternidades, verifica-se que os estudos separados e específicos sobre gênero, sexualidade, camada social ou etnia/raça não dão conta dos processos de interseccionalidade em que as subalternidades engendram práticas opressoras muito mais contundentes. Assim, numa tentativa de compreender esses processos de subalternização, que não podem ser entendidos isoladamente, lança-se mão da articulação de categorias vinculadas à camada social, ao gênero, à sexualidade, à etnia/raça, ou seja, trabalha-se com a interseccionalidade (DAVIS, 2016; GOMES, 1996, 2012; PISCITELLI, 2008).

O conceito de interseccionalidade busca dar conta de uma das principais tensões no campo de produção de conhecimento das Ciências Sociais e da Sociologia da Educação, isto é, uma possível articulação entre estrutura e agência, suas representações simbólicas e a dominação social. Nesse percurso, a principal função do conceito de interseccionalidade é a possibilidade de compreender normas, valores, discursos e ideologias. Ressalta-se que estruturas sociais e identidades se influenciam mutuamente, permitindo desnaturalizar formas de legitimação e justificação da injusta subalternidade social (CRENSHAW, 2002; MATTOS, 2011; STOLKE, 2006).

Segundo Patrícia Mattos, a abordagem interseccionalidade contribui na percepção dos distintos efeitos que as categorias de diferenciação produzem em contextos específicos:

Um dos aspectos centrais dessa abordagem interseccional diz respeito à necessidade de se perceber que as categorias de diferenciação produzem efeitos distintos, dependendo do contexto analisado. Portanto, a escolha das categorias de diferenciação nos diferentes níveis de análise deve levar em consideração esse aspecto levantado em relação às causas e aos efeitos, reconhecendo sempre que a especificidade histórica e contextual distingue mecanismos que produzem, estabilizam, perpetuam e naturalizam desigualdades sociais por diferentes divisões categoriais. A forma de investigar as desigualdades sociais e as discriminações nos níveis da estrutura social, das representações simbólicas e da identidade é diferenciada (2011, p. 3).

Dessa maneira, brinquedos e brincadeiras, comportamentos, roupas, profissões, sonhos, desejos, práticas esportivas, interações sociais, tanto no espaço privado (seus lares), 
como no espaço público decorrem dessas estruturas sociais, das representações simbólicas e da identidade na construção da realidade social (MATTOS, 2011; SCOTT, 1996).

Nesse processo de socialização e sociabilidade, a escola, assim como seu corpo docente e sua equipe gestora, é constituída, em relação ao sexo, gênero, sexualidade, etnia-raça e camada social que têm seus sentidos condensados, por meio da inteligibilidade social, em categorias dicotômicas de macho-fêmea, homem-mulher, branco-negro, pobre-rico. Nesse caminho, é impossível pensar sobre a instituição educacional sem as construções sociais e culturais acerca dessas categorias dicotômicas hierarquizadas (BATISTA, 2013; DAVIS, 2016; GOMES, 1996; LOURO, 1997; MIRANDA, 2011; MISKOLCI, 2012; OLIVEIRA, 2012).

Guacira Louro (1997) reflete que, para alguns autores, a escola é feminina porque é primordialmente um lugar de atuação de mulheres, que organizam e ocupam o espaço, elas são as professoras, são as gestoras. Ou seja, a atividade escolar é marcada pelo cuidado, vigilância e educação, tarefas que são tradicionalmente consideradas femininas. No entanto, para outros, a escola é masculina, uma vez que lida, fundamentalmente, com conhecimento, e esse "conhecimento" foi, historicamente, produzido pelos homens; dessa forma, mesmo que as docentes sejam mulheres, elas se ocupariam de um universo marcadamente masculino, porque é centrado no conhecimento.

Tais processos de inteligibilidade social que materializam corpos de macho e fêmea, de homem e de mulher, brancos e negros, heterossexuais e homossexuais são ficcionais. Isto é, essas identidades e desejos dependem de como os indivíduos são interpelados por meio da condensação de sentidos nas categorias de compreensão da realidade social.

Entretanto, a materialização dos desejos vem demonstrando que os agentes sociais não são cem por cento engendrados nesse processo de inteligibilidade heteronormativo de categorias dicotômicas, excludentes e hierarquizadas entre macho-fêmea, homem-mulher, heterossexual-homossexual. Há "falhas". Os casais heterossexuais que preferem práticas sexuais invertidas de penetração; os/as crossdressing, as parodias corporais, tais como: as travestis, os/as transgêneros e as drag queens e os drag kings demonstram que há uma separação/descolagem das categorias de sexo, gênero e sexualidade. Assim, um corpo masculino necessariamente não tem de materializar um "homem", nem uma heterossexualidade (BUTLER, 2003, 2008, MIRANDA, 2013).

Entretanto, infelizmente, na sociedade brasileira, ainda há atitudes preconceituosas e discriminatórias que engendram uma cultura predominantemente 
lesbofóbica, homofóbica, transfóbica e racista, presenciada nas ruas, nas religiões evangélicas (pentecostais e neopentecostais) e, principalmente, nas famílias e nas escolas.

Vale ressaltar que a família e a escola, infelizmente, que deveriam ser espaços de proteção e acolhimento, são as instituições mais LGTBfóbicas ${ }^{3}$ em nossa sociedade. (BORILLO, 2010; PRADO; JUNQUEIRA，2011; RAMIRES，2011; VENTURI; BOKANY, 2011).

Nesse caminho, a população LGBT é discriminada, rechaçada, excluída, sofrendo violências simbólicas, físicas e até sexuais. E se essa população LGBT tiver outros marcadores sociais de diferença - tais como, ser mulher, negra e pobre -, a violência ganha proporções consideráveis, pois há intersecção dessas categorias de subalternidades.

Essas práticas sociais, nas escolas, resultam em dois aspectos: a) em um alto índice de violências físicas, emocionais, sexuais, racistas praticadas pelos colegas, docentes e gestão contra docentes e discentes que não correspondem ao comportamento da heterossexualidade compulsória ou da heteronormatividade branca; b) em violência simbólica e ou física que comprometem a qualidade da educação e o rendimento escolar influenciam negativamente na retenção, na reprodução de desigualdades sociais e ou na expulsão desses discentes dos ambientes educacionais, caracterizando uma pedagogia excludente.

São perceptíveis, já na educação básica, os índices alarmantes de violência física e emocional contra criança e adolescentes, ocasionados por seus colegas, por docentes, e gestores e por parte da sociedade tradicional, machista, LGBTfóbica e racista. Tal contexto de violência escolar pode ser compreendido pela relação entre bullying, racismo e LGBTfobia. Esse último termo problematizando as relações de poder e denunciando uma estrutura de inteligibilidade da heterossexualidade compulsória e ou heteronormativa que contribui na compreensão de quem são os grupos alvos e das práticas do bullying no ambiente escolar (BATISTA, 2013; DIAZ, SOUZA, 2010, GARCIA, 2009; SILVA, BARRETO, 2012; SILVA, SALLES, 2010).

Nessa perspectiva, Fante (2005) afirma que o bullying está relacionado a um conjunto de atividades:

agressivas, intencionais e repetitivas que ocorrem sem motivação evidente, adotadas por um ou mais alunos contra outro(s), causando dor,

\footnotetext{
${ }^{3} \mathrm{O}$ termo clássico utilizado na literatura é homofobia definida como atitudes de hostilidades contra as/os homossexuais (BORRILLO, 2010). Com a finalidade de marcar as violências especificas de lésbicas e pessoas transgêneros, vem sendo empregado o termo LGBTfobia.
} 
angústia e sofrimento. Insultos, intimidação, apelidos cruéis, gozações que magoam profundamente, acusações injustas, atuação de grupos que hostilizam, ridicularizam e infernizam a vida de outros alunos levando-os a exclusão, além de danos físicos, morais e materiais, são algumas das manifestações do comportamento bullying (2005, p. 29).

Lamentavelmente, as abordagens sobre as temáticas de gênero e da promoção ao respeito à diversidade sexual, conquistadas nos primeiros planos nacional, estaduais e municipais de educação, foram retiradas dos atuais planos de educação (PNE, 2014; PEE, 2015) e da Base Nacional Comum Curricular (BNCC, 2016) por setores fundamentalistas presentes no poder legislativo. Essa exclusão da diversidade/diferença nega o dever do Estado em atender às demandas e à promoção de direitos às mulheres e à comunidade de lésbicas, gays, bissexuais e transgêneros (travestis e transexuais) (LGBT). O silêncio/invisibilidade da diferença nas questões de gênero e homossexualidade reforça a prática social da violência contra a comunidade LGBT e o lugar da instituição educacional como reprodutivista da desigualdade de gênero e LGBTfóbica.

Outra grande perda em relação ao respeito aos direitos humanos e à cidadania é descaracterização do Estado brasileiro como laico, por meio da publicação, no Diário Oficial de Pernambuco (2015), do Projeto de Lei elaborado pela bancada evangélica que proíbe o ensino de qualquer temática relacionada às questões de gênero, no âmbito educacional.

Reforçando o contexto acima de violação dos direitos humanos e desrespeito à diversidade/diferença, o Ministério das Mulheres, da Igualdade Racial e dos Direitos Humanos fez uma pesquisa e expõe que Pernambuco ocupa o segundo lugar no país, em números de mortes de pessoas LGBT. Esse número fica ainda mais gritante ao articular a categoria raça (JORNAL EXTRA DE PERNAMBUCO, p. 07, 2016).

Outro aspecto que destacamos diz respeito ao racismo praticado no cotidiano educacional, presente da Educação Infantil à Pós-Graduação. Tal prática resulta de um processo histórico da constituição de um Estado racista, promovendo uma política de branqueamento; da divulgação do mito de uma democracia racial que oculta e perpetua um processo de exclusão, sobretudo, na interseccionalidade entre os marcadores sociais de classe social, raça/etnia, gênero e sexualidade (BATISTA, 2013; MATTOS, 2011).

No entanto, não há apenas notícias negativas. Em resposta a tais violações dos direitos humanos, foi publicada, no Diário Oficial da União, a Lei ${ }^{\circ} 13.185 / 2015$, que combate o bullying na sociedade brasileira, colocando a escola como um local 
privilegiado em promover uma educação antibullying. A referida lei centra suas ações no combate às intimidações sistemáticas (bullying) que podem ser compreendidas como:

todo ato de violência física ou psicológica, intencional e repetitivo que ocorre sem motivação evidente, praticado por indivíduo ou grupo, contra uma ou mais pessoas, com o objetivo de intimidá-la ou agredi-la, causando dor e angústia à vítima, em uma relação de desequilíbrio de poder entre as partes envolvidas (BRASIL, 2015).

Assim, a instituição educacional se constitui como um lócus de socialização e sociabilidades, possibilitando desnaturalizar e problematizar subalternidades. Nesse caminho, ao eleger a instituição educacional como principal lugar de processo de socialização de uma cultura antibullying, a Lei $n^{\circ}$ 13.185/2015 indica que a escola tem o dever de:

prevenir e combater a prática da intimidação sistemática (bullying) (...); capacitar docentes e equipes pedagógicas para a implementação das ações de discussão, prevenção, orientação e solução do problema; implementar e disseminar campanhas de educação, conscientização e informação; instituir práticas de conduta e orientação de pais, familiares e responsáveis diante da identificação de vítimas e agressores; integrar os meios de comunicação de massa com as escolas e a sociedade, como forma de identificação e conscientização do problema e forma de preveni-lo e combatê-lo (...) (BRASIL, 2015).

Considerando tais aspectos, a escola, como instituição social e promotora de uma educação para os direitos humanos, tem o dever de oferecer um ambiente de incentivo ao reconhecimento, à inclusão em relação às classes sociais e à etnia-raça, assim como a promoção de equidades de gênero e respeito às diferenças sexuais, dentre outras.

Tendo por base esse contexto, essa pesquisa tem, como objetivo geral, investigar como duas escolas de referências do Ensino Médio, na cidade de Caruaru/PE, promovem uma educação para os direitos humanos no fortalecimento do combate ao racismo e à LGBTfobia via uma pedagogia antibullying. E, como objetivos específicos: a) analisar a prática pedagógica, na sala de aula do componente disciplinar dos direitos humanos sobre as temáticas de gênero, sexualidade e etnia-raça; b) verificar se há promoção de um ambiente de incentivo às equidades de gênero e respeito às diferenças sexuais e de etnia-raça. 


\section{ASPECTOS METODOLÓGICOS}

A pesquisa tem como foco a análise da prática pedagógica, na sala de aula do componente disciplinar dos direitos humanos sobre as temáticas de gênero, sexualidade e etnia-raça. A partir desse foco, foram escolhidas escolas de referência, porque em tais escolas há a obrigatoriedade da oferta do componente curricular de Direitos Humanos. Assim, a nossa análise empírica recaiu nas práticas pedagógicas dos docentes da referida disciplina de Direitos Humanos.

O método de análise utilizado foi a Análise de Conteúdo (AC). Esse método teve como finalidade categorizar as falas dos docentes por meio das conversas informais no que diz respeito aos seus pensamentos, sentimentos, memórias. A AC possibilitou a categorização do material coletado por meio de inferência sobre os dados coletados via conversas informais, observações e entrevistas semiestruturadas, ou seja, de um texto focal para o contexto social da prática docente no cotidiano do componente disciplinar de direitos humanos de uma maneira objetiva (BAUER, 2010).

Nessa perspectiva, a AC é constituída por dois procedimentos de análise: sintáticos e semânticos:

Nos permite reconstruir indicadores e cosmovisões, valores, atitudes, opiniões, preconceitos e estereótipos e compará-los entre comunidades (...) [Assim] os procedimentos da AC reconstroem representações em duas dimensões principais: a sintática e a semântica. Procedimentos sintáticos se enfocam os transmissores de sinais e suas inter-relações. (...). A frequência das palavras e sua ordenação, o vocabulário, os tipos de palavras e as características gramaticais e estilísticas são indicadores de uma forte e da probabilidade de influência sobre alguma audiência. (...) Os procedimentos semânticos dirigem seu foco para a relação entre sinais e seu sentido normal - sentidos denotativos e conotativos em um texto. (...) Palavras, sentenças e unidades maiores de textos são classificados como exemplos de temas predefinidos e avaliações (BAUER, 2010, p. 192-193)

A partir do exposto acima, busca-se reconstruir "mapas de conhecimentos" por meio dos textos analisados via a AC. Assim, os docentes que ensinam o componente curricular de direitos humanos nas Escolas de Referência, da Educação Básica, do agreste pernambucano utilizam suas falas para representar o mundo conhecimento e autoconhecimento. Nesse sentido, utilizamos a AC como referência na construção de redes de unidades de análises em relação aos elementos e às suas relações para alcançar os objetivos específicos de: a) analisar, a prática pedagógica, na sala de aula do 
componente disciplinar dos direitos humanos sobre as temáticas de gênero, sexualidade e etnia-raça; b) verificar se há promoção de um ambiente de incentivo às equidades de gênero e respeito às diferenças sexuais e de etnia-raça (BAUER, 2010).

Levando em consideração a exposição do método de análise da AC, foram utilizadas as seguintes técnicas de coletas de dados: a) conversas informais e b) observação não participante.

A técnica de coleta de dados, por meio das conversas informais, permitiu que os pesquisadores obtivessem informações sobre a prática pedagógica de ensino de direitos humanos, rompendo com a formalidade e a tensão, muitas vezes provocada pelas entrevistas semiestruturadas. Dessa maneira, os docentes pesquisados puderam se sentir mais tranquilos para emitirem seus valores, representações e análises sobre sua vivência cotidiana do ensino de direitos humanos.

A observação não participante possibilitou que os pesquisadores chegassem mais próximos do mundo simbólico dos docentes estudados, uma vez que puderam acompanhar o cotidiano da prática pedagógica escolar do ensino de direitos humanos (LÜDKE; ANDRÉ, 2014). Essas técnicas possibilitam o acesso ao mundo subjetivo (GASKELL, 2010) das interações, tanto via conversas informais quanto por meio da observação das práticas pedagógicas na sala de aula entre docente-discente e discentediscente. A partir da coleta desses dados, pudemos mapear se há ou não uma possível construção de uma cultura de fortalecimento dos direitos humanos, com respeito às diferenças em um ambiente democrático.

Além dessas técnicas acima citadas, foi realizada a entrevista semiestruturada. Essa técnica de coleta de dados foi escolhida com a finalidade captar, de forma imediata e pessoal, as informações junto aos docentes de direitos humanos em suas práticas cotidianas. Ou seja, buscamos, por meio das verbalizações dos nossos entrevistados, as dificuldades enfrentadas e/ou vantagens adquiridas na prática do componente curricular dos direitos humanos nas escolas de referências da Educação Básica do agreste de Pernambuco (LÜDKE; ANDRÉ, 2014).

Nesse caminho, o roteiro de entrevista semiestruturada foi aplicado com os docentes da disciplina de Direitos Humanos. Realizou-se, assim, um total de duas entrevistas com professores das referidas escolas que ministram aulas de Direitos Humanos. Todas as entrevistas foram gravadas com a finalidade de registrar o máximo de informação possível para posteriores averiguações. 


\section{COMPREENDENDO A VIDA SOCIAL DA PRÁTICA PEDAGÓGICA DO ENSINO DE DIREITOS HUMANOS}

Esse tópico será dividido em três subitens: o primeiro tem a finalidade de indicar o local da estrutura social em que estão situados os docentes da pesquisa; o segundo subitem descreve as escolas do agreste pernambucano que fizeram parte da pesquisa; e o terceiro, mapeia os aspectos simbólicos que constituem o mundo subjetivo dos entrevistados que guiam suas práticas sociais. Dessa maneira, ao se tentar compreender os dados expostos nos três subitens, buscou-se alcançar os objetivos específicos dessa pesquisa: a) analisar a prática pedagógica na sala de aula do componente disciplinar dos direitos humanos sobre as temáticas de gênero, sexualidade e etnia-raça; b) verificar se há promoção de um ambiente de incentivo às equidades de gênero e respeito às diferenças sexuais e de etnia-raça.

\subsection{Situando os docentes na estrutura social}

Por meio da entrevista semiestruturada, conseguimos expor que, na escola A, o professor 1 tem 38 anos de idade, é do gênero masculino, católico, casado e formado no ano de 2002, em História, pela UFRPE. Já na escola B, o professor 2 tem 52 anos de idade, também é do gênero masculino, católico, casado, formado no ano de $1986 \mathrm{em}$ História, pela FAFICA, faculdade localizada no interior do estado de Pernambuco, na cidade Caruaru. Em relação ao seu fenótipo, esse docente é pardo e tem características físicas relacionadas aos afro-descendentes.

Quanto ao nível de instrução dos familiares, os pais do Professor 1 possuem Educação Básica completa. Seu pai trabalhou como vendedor e a mãe "do lar". Em relação à cônjuge, a esposa do professor 1 possui Ensino Superior e exerce o cargo de administradora de empresas. O professor tem um irmão com 36 anos com nível de escolaridade do Ensino Médio. O irmão do referido docente trabalha em uma empresa de construção civil.

Em relação ao Professor 2, que ministra aula na escola B, seu pai é formado em Direito e atua como advogado, divorciado, tem 46 anos de idade, de cor branca. Sua mãe tem Ensino Médio, mas não exerce atividade remunerada, sendo do lar. O referido docente tem um único irmão com 51 anos de idade, escolaridade de nível do Ensino médio e trabalha na Secretaria de Saúde de Caruaru. 
Fazendo uma análise no quadro social das famílias dos dois docentes, podemos notar que suas famílias são de camada média e que os pais se constituíram como provedores econômicos de suas famílias, enquanto às mães cabia a responsabilidade do cuidado do lar e dos filhos. Tal situação na divisão sexual do trabalho, nas famílias de origem dos docentes sujeitos de nossa pesquisa, ratifica os níveis diferenciados e hierarquizados de ocupação entre homens e mulheres, já bastante apontados por vários trabalhos científicos (BRUSCHINI, 1994; MIRANDA, 2011; SAFFIOTI, 1996). Contudo, destacamos que, na nova família constituída pelo professor 1, sua esposa trabalha fora do lar.

Dessa maneira, podemos inferir que, sendo suas famílias heteronormativas, os dois docentes não tiveram uma experiência com organizações familiares mais alternativas, tais como famílias constituídas apenas por uma mãe ou apenas por um pai, famílias homoparentais (formadas por duas mães ou dois pais) (SCOTT, 1999). Se os docentes tivessem vivenciado essa situação, poderiam ter outra experiência que repercutiria em sua prática pedagógica somada à sua formação docente inicial e continuada.

\subsection{As escolas pesquisadas do agreste de Pernambuco}

- Escola A

De início, é importante mencionar que houve resistências da gestão da escola em relação à referida pesquisa. Tal resistência foi percebida por meio das dificuldades colocadas por parte da equipe gestora da escola em atender aos pesquisadores e os deixar participarem do cotidiano escolar e/ou acompanhar/observar as aulas de direitos humanos do professor 1, durante os três meses de realização da pesquisa de campo. No entanto, ao se persistir na realização da pesquisa, conseguimos ultrapassar as barreiras iniciais e dá prosseguimento ao estudo.

Assim, por meio de conversa informal com o professor 1, foi-nos informado que, no ano de 2017, a primeira unidade escolar foi um tanto conturbada. Os horários ainda não estavam definidos para a disciplina de Direitos Humanos (DH). Tal ausência de horário resultou que a disciplina de $\mathrm{DH}$ foi preenchida com as sobras da carga horária de outras disciplinas dos horários dos professores. Ou seja, só se ministrava a disciplina de DH quando algum docente de outras disciplinas faltava às aulas e a disciplina de DH servia para preencher as lacunas e ausências das contingenciais dos outros componentes disciplinares. 
Dessa constatação, pode-se inferir que a disciplina DH não é uma prioridade na escola A. Nesse caminho, os conteúdos de uma educação para os Direitos Humanos ficam ameaçados ou em segundo ou terceiro planos de importância em relação a outros componentes curriculares da matriz curricular. Esse procedimento compromete uma educação de promoção de cidadania e de respeito à diversidade/diferença em relação ao gênero, sexualidade e etnia-raça.

Segundo o Professor 1, devido à instabilidade e à troca de professores que ministravam a disciplina de DH no primeiro semestre de 2017, "sobrou" poucas aulas para trabalhar os conteúdos que estavam programados dos Direitos Humanos relativos à primeira unidade do ano letivo. Dessa maneira, a prática pedagógica desse docente se restringiu apenas à divisão da turma em quatro grupos para a realização de quatro seminários com as seguintes temáticas: a) Direitos das mulheres e o machismo; b) LGBT - Preconceitos e Discriminação; c) ECA - Criança e Adolescente; e d) Racismo.

Ressaltamos que, em meio às apresentações, o Professor 1 foi fazendo considerações e abrindo espaços para debates, baseado no exposto por cada grupo. Desse modo, a prática pedagógica do ensino e aprendizagem dos temas relacionados aos direitos humanos ficou a cargo das iniciativas de cada grupo de seminário, sem ter uma bibliografia de referência guiada e escolhida pelo docente. Nessa perspectiva, as referidas temáticas foram desenvolvidas superficialmente apenas no momento de exposição de cada grupo de seminário.

Essa ausência do docente em guiar o processo de ensino e aprendizado sobre as temáticas dos DH reflete na falta de preparo por parte das políticas de formação docente com os profissionais da educação dos direitos humanos. Vale ressaltar que os referidos temas abordados pelos grupos nos seminários são densos e constituem profundos campos de produção de conhecimento nas ciências sociais e humanos. Entretanto, como não houve políticas de formação docente inicial e continuada, os referidos temas acabaram sendo trabalhados de maneira insatisfatória. Em outras palavras, não há uma materialização de uma educação de promoção da democracia, do respeito à cidadania e do combate ao bullying com os grupos que, tradicionalmente, são excluídos em nossa sociedade: população LGBT, afro-descendentes e camadas populares.

\section{- Escola B}

$\mathrm{Na}$ escola B, os pesquisadores tiveram uma recepção diferente do que aconteceu na escola $\mathrm{A}$. Na instituição $\mathrm{B}$, não houve resistência por parte dos gestores, nem se 
observaram quaisquer obstáculos em receber os pesquisadores, pois permitiram acesso ao professor responsável pelo componente curricular de direitos humanos, sem dificultarem a realização da pesquisa.

A motivação da escolha dessa referida escola se deu pela ocorrência de situações homofóbicas vivenciadas nessa instituição, segundo informações de estudante egresso. Entretanto, por meio de conversas informais com esse estudante egresso e docentes da instituição educacional, soubemos que a equipe gestora e alguns docentes organizaram palestras com profissionais da psicologia para os discentes, problematizando preconceitos, misoginia, machismo, racismo e LGBTfobia, ao mesmo tempo em que tais palestras promoviam o respeito à diversidade. Vale ressaltar que mais adiante traremos a fala do docente entrevistado a esse respeito.

Assim, a escola se posicionou de uma forma de promoção da democracia e da cidadania, materializando uma educação dos Direitos Humanos. Ressaltamos, ainda, que, durante a visita, realizamos a entrevista com o professor que ministra o componente curricular de Direitos Humanos - que ajudou a combater e problematizar o caso de LGBTfobia acontecido naquela instituição educacional.

\subsection{Acessando o mundo simbólico dos docentes}

Como mencionado anteriormente, voltamos a realizar uma entrevista semiestruturada na escola $\mathrm{B}$, com a finalidade de analisar as concepções do docente em relação às temáticas de gênero, sexualidade e etnia-raça. As entrevistas buscavam levantar dados em relação a uma educação para os Direitos Humanos, por meio de uma pedagogia antibullying.

Vale ressaltar que a Lei $\mathrm{n}^{\mathrm{o}} 13.185 / 2015$, antibullying, coloca a escola como o espaço privilegiado, com o dever de prevenir e combater a prática de bullying por meio da capacitação dos professores e professoras e das equipes gestora. Nessa perspectiva, as práticas pedagógicas devem promover problematizações, debates, orientações, informações e conscientizações, com a finalidade de encontrar soluções para ultrapassar o problema do bullying (BRASIL, 2015). Destacamos que as principais vítimas do bullying são a população LGBT, afrodescendente, indivíduos de camadas populares, etc. Ou seja, há uma possibilidade muito maior de sofrerem bullying as pessoas que se encontram em diversas subalternidades reforçadas pela interseccionalidade de gênero, sexualidade, etnia-raça (DAVIS, 2016; GOMES, 1996; MATTOS, 2011; STOLKE, 2006). 
Tanto o docente da Escola A como o docente da escola B alegaram que já tiveram alunos e alunas com comportamentos diferentes daqueles considerados hegemônicos para cada sexo/corpo, gênero e orientação sexual. Isto é, em ambas as escolas, havia ou há discentes que excediam a heterossexualidade compulsória relacionada a uma inteligibilidade que condensa sentidos da sexualidade como obrigatória ou a heterossexualidade normativa, que estabelece uma lógica em que até se aceita a homossexualidade, desde que corresponda aos modelos do comportamento heterossexual: o gay seja "másculo" e ou "discreto" e a lésbica seja "feminina" e ou “discreta” (MIRANDA, 2013; MISKOLCI, 2012).

Ratificando a ideia da heteronormatividade exposta acima, na escola A, segundo o professor 1, é difícil perceber algum aluno homossexual, pois são mais discretos: “difícil de perceber essas coisas porque são mais discretos e eu não sou de perceber".

Foi perguntado aos docentes das duas escolas como os outros alunos e as outras alunas lidavam com os alunos e alunas "diferentes" e os docentes responderam mais sucintamente:

hoje em dia é normal" (PROFESSOR 1).

Aqui nessa escola a gente não encontra muito preconceito, tem algumas brincadeiras, mas nada assim que chame atenção (PROFESSOR 2).

Analisando as falas dos professores, podemos inferir que o preconceito foi minimizado quando os docentes naturalizam possíveis formas de bullying que podem existir no cotidiano escolar com os discentes e as discentes considerados diferentes.

No entanto, em consonância ao que foi dito anteriormente sobre a escola B ter alguma ação no combate ao bullying, o professor 2 toma ações que contribuem para combater tal violência na escola. Tal situação pôde ser percebida a partir das respostas dadas sobre suas práticas pedagógicas e de combate ao bullying.

Tentar mostrar, sensibilizar e mostrar que a vida do outro não interessa a ninguém. O que o outro faz com seu corpo é problema dele. Então, a gente coloca sempre essa questão: Por que você se incomoda que o outro é diferente de você? Se o outro é homossexual, bi, por que ele incomoda? É a vida dele. Então, o problema não estaria naquele que está promovendo aquela reação negativa a aquele que é dito diferente? (PROFESSOR 2).

Todavia, o docente 1 dá uma resposta mais geral, sem especificar de que forma sua prática pedagógica contribui, efetivamente, no combate ao bullying. 
Fazer o que eu já faço: trabalhar a questão da alteridade, do respeito (...) e eles já têm essas informações (...). Esse tipo de coisa não acontece, pelo menos na minha comunidade escolar. Quer dizer, deve ter algumas pessoas que pensam assim, mas talvez não externem (PROFESSOR 1).

Por um lado, podemos notar que o professor 1 nega a existência de preconceito quando diz que "esse tipo de coisa não acontece". Embora o docente reconheça logo após expressar a negação que possa existir algum tipo de preconceito, ele nega a existência de esse preconceito ser assumido no seu ambiente escolar. Pensar que não existe a demonstração do preconceito é pensar que não teríamos, também, a existência do bullying e sabe-se que, no cotidiano da instituição educacional, a LGBTfobia existe e está muito dentro das salas de aula, nos pátios dos colégios, no horário do recreio, nos jogos e nas brincadeiras (BATISTA, 2013; BORILLO, 2010; DIAZ; SOUZA, 2010; GARCIA, 2009; GOMES, 1996; LOURO, 1997).

Por outro lado, o professor 2 sugere, como prática pedagógica, a promoção de diálogos e incentivo ao pensamento crítico e à conscientização por parte dos discentes e das discentes. Tais ações se configuram como uma prática pedagógica pertinente a uma educação para os direitos humanos (CANDAU et al, 2013; CANDAU; SACAVINO, 2013; RODINO, 2012) reforçando o respeito à diversidade e combatendo a discriminação e o bullying .

É importante mencionar, ainda, que, quando foi perguntado ao professor 2 sobre o que a escola (gestão, coordenação, docentes) fez diante de situações vivenciadas de preconceito, discriminação, machismo, sexismo e racismo, o docente respondeu que houve um acontecimento na escola que estava se agravando e que a equipe gestora e docentes acharam pertinente pedir ajuda a outros profissionais, externos à escola. Nas palavras do professor:

Esse ano, a gente se deparou com uma situação envolvendo o machismo, a misoginia, a homofobia. Então alguns professores, junto com a escola, chamaram duas psicólogas que trabalham com jovens e adolescentes. Elas trabalharam com apenas um $2^{\circ}$ ano, que foi justamente o que estavam tendo esses casos de preconceito. E foi muito bom, porque elas falaram de orientação sexual, de sexualidade, de namoro e um monte de assunto que eles ficaram bem à vontade. Inclusive ela pediu para que fosse uma roda de conversa e não uma palestra. A gente já percebeu mudanças sensíveis. Justamente aqueles que eram mais radicais com relação a isso. Eles mudaram 0 comportamento (PROFESSOR 2). 
Logo, na fala do docente, pode-se notar que a postura pedagógica da escola B contribuiu para uma mudança de atitude e valorização das diferenças. Tal postura está em harmonia com o que a Lei Antibullying propõe ao colocar a instituição escolar como uma das principais responsáveis por uma pedagogia antibullying e promoção de uma educação em e para os direitos humanos (CANDAU et al, 2013; CANDAU; SACAVINO, 2013; RODINO, 2012).

Porém, apesar de iniciativa dos profissionais da escola $\mathrm{B}$, o que se constatou é que os docentes não têm formação inicial nem continuada para trabalharem as temáticas de gênero, de orientação sexual, de pessoas trans (transexuais e travestis), nem a cultura e a história dos afrodescentes (MESSIAS, 2010; MISKOLCI, 2010; OLIVEIRA, 2012).

Essa falta de formação inicial e continuada foi mencionada na fala do professor 1, da escola A, que ministra o componente curricular de direitos humanos: "não tenho muito contato, pois não é a minha área de atuação [profissional]".

Assim, seguindo no mesmo caminho do exposto acima, os dois docentes entrevistados alegam que não foram capacitados em sua formação profissional; que essa capacitação não foi suficiente, ocasionando uma formação precária ou, ainda, colocando a responsabilidade nas dificuldades dos docentes em mudarem na direção do respeito à diversidade e à promoção da cidadania:

Como sempre tem algo novo (...) e é importante está se atualizando. $\mathrm{O}$ governo do estado só deu algumas capacitações no começo e nunca mais tivemos. No meu caso, eu procuro me atualizar por iniciativa própria, a participar de cursos online (...) está sempre lendo (...) (PROFESSOR 2).

Há ignorância, porque você pode pegar meia dúzia de professores e você pode passar dez anos com eles promovendo cursos e eles não vão mudar. $\mathrm{E}$ às vezes se espera muito de um professor da área de humanas. (...) A questão da politização dos professores e a consciência de cada um, é de cada um, já são todos formados. (PROFESSOR 1).

O professor 1 dá espaço para a questão da não aceitação, por alguns professores, do ensino sobre orientação sexual, relações de gênero na escola e equidade racial. Geralmente, esse fato acontece, pois muitos professores envolvidos em questões de fundamentalismo religioso acabam não aceitando a discussão em sala de aula dessas questões, demonizando a cultura afro-brasileira e a população LGBT. Dessa maneira, não há uma consciência, por parte do docente, de uma ausência da formação profissional pedagógica e do seu papel de socialização e sociabilidade em prol de uma educação em e para os direitos humanos (CANDAU et al, 2013; CANDAU; SACAVINO, 2013; RODINO, 2012). 
Já o professor 2 discute sobre a importância da promoção de capacitações para manter atualizada as discussões e informações sobre as temáticas de gênero, sexualidade e equidade racial.

Dessa forma, os docentes vão amadoristicamente focando suas discussões e práticas pedagógicas, de forma geral, nas temáticas sobre doenças sexualmente transmissíveis (DST), gravidez na adolescência e orientação sexual. Se os docentes tivessem formação inicial e continuada em prol de uma educação democrática e de valorização dos direitos humanos, as práticas pedagógicas poderiam ser muito mais eficazes.

Para finalizar, perguntou-se aos dois professores que opinião eles tinham sobre pobreza, população afro-descente e ações preconceituosas, discriminatórias, racistas e de prática de bullying, sofrendo intersecção com gênero e sexualidade. Os dois docentes verbalizaram as opiniões abaixo:

Não. Existe uma questão social por trás, mas o preconceito é independente de raça, religião. Você fala que não é racista porque não tem nada contra negros, mas você recrimina o candomblé dizendo que é macumba. Como é que não vai dizer que é racista? Você está sendo contra a expressão cultural do negro. Porque na realidade, eu sou contra a religião do outro. Porque parte do princípio de ser o outro e esse outro ser é o negro (PROFESSOR 1).

A nossa sociedade patriarcal via a mulher como um objeto do homem (...). Então inferioriza o gênero feminino. Aí vem a inferiorização (sic) também da mulher negra, do homem negro, do mais pobre e assim sucessivamente (...). E o homossexual masculino, por exemplo, (...) se ele tem muitos trejeitos, muito feminino aí ele também é inferiorizado. Essas relações de poder estão embutidas nessas relações de gênero (PROFESSOR 2).

As verbalizações do professor 1 contém o reconhecimento do racismo, principalmente em relação às religiões de matriz africanas como o candomblé. No entanto, o referido docente não estabelece uma relação de forma explícita entre etniaraça, pobreza, gênero e sexualidade. Porém, podemos inferir, baseados em diversas pesquisadoras e pesquisadores indicados (COSTA, 2012; CRENSHAW, 2002; DAVIS, 2016; GOMES, 1996; MESSIAS, 2010; MISKOLCI, 2010; OLIVEIRA, 2012; STOLKE, 2006), que a sociedade brasileira, entre outras sociedades ocidentais, assim como o Estado, impõe uma subalternidade muito mais intensa às pessoas pobres, negras, mulheres e lésbicas.

A fala do professor 2 pode ser ratificada pelas análises das pesquisadoras e dos pesquisadores indicados acima no que diz respeito à possibilidade de um indivíduo 
viver, simultaneamente, várias condições de subordinação, em que a camada social, a raça-etnia, o gênero e a sexualidade se interseccionam e intensificam a discriminação, a exclusão, a estereotipia e o preconceito. Para o referido professor, as relações de poder, na sociedade, podem ter como consequência múltiplas formas de subalternização. Não é por acaso que a pobreza no Brasil tem cor, a comunidade carcerária também tem cor. No mercado sexual dos garotos e garotas de programas, das travestis, a "carne mais barata é a carne negra", ou seja, a interseccionalidade resulta na materialização dos corpos como abjetos. Isto é, a sociedade considera esses indivíduos que interseccionam subalternidades, sendo categorizados como não humanos (BUTLER, 2003; CARRARA, 2006; PERLONGHER, 1987).

Nessa perspectiva, o bullying praticado no cotidiano escolar contra mulheres, negros, pobres, LGBT pode ser considerado como um caminho de inteligibilidade social que os categoriza como abjetos (BATISTA, 2013; DIAZ, 2010). Daí a importância de se ter formação docente nos cursos de licenciatura para uma educação em e para os direitos humanos. E que essa formação resulte em uma prática pedagógica de fortalecimento da democracia, promoção da cidadania e respeito à diversidade, pois "se a educação sozinha, não transforma a sociedade, sem ela tampouco a sociedade muda." (FREIRE, 2000, p. 67). Assim, todo o nosso compromisso como educares é que a educação não seja reprodutivista da desigualdade social, mas que o processo educativo contribua para subverter e transformar a ordem social opressora.

\section{CONSIDERAÇÕES FINAIS}

Retomando os nossos objetivos específicos com a finalidade de respondê-los: a) analisar a prática pedagógica na sala de aula do componente disciplinar dos direitos humanos sobre as temáticas de gênero, sexualidade e etnia-raça; b) verificar se há promoção de um ambiente de incentivo às equidades de gênero e respeito às diferenças sexuais e de etnia-raça. Podemos destacar que a inserção de temas que promovem uma educação para o respeito às diferenças está sendo incluída timidamente nas práticas pedagógicas dos docentes entrevistados por meio do componente disciplinar dos direitos humanos.

Os docentes das duas escolas deixam transparecer como ainda é forte uma educação reprodutivista da desigualdade social, concretizando práticas de bullying sobre a intersecção das subalternidades de gênero, sexualidade, etnia-raça e camada 
social. Tais injustiças são justificadas por um discurso neoliberal e neoconservador, baseado na meritocracia, que tem a finalidade de encobrir as desigualdades sociais, focando em uma lógica individualista sem fazer uma análise crítica sobre igualdade de oportunidades e do percurso histórico desses indivíduos subalternizados.

No entanto, faz-se necessária uma profissionalização da atividade docente por meio de uma formação inicial e continuada em que haja o aprofundamento e a intensificação dos conhecimentos sobre direitos humanos, respeito à diversidade, gênero, etnia-raça e sexualidade. Tais ações poderiam refletir em uma educação cidadã por meio de debates, projetos e pesquisas que desnaturalizem e ou problematizem as desigualdades sobre os indivíduos que interseccionam subalternidades expostas nesse texto. Essa mudança na prática pedagógica possibilita que se vá atenuando o preconceito, discriminação, sexismo, misoginia e LGBTfobia, tão presentes em nossa história.

De maneira mais específica, a promoção da capacitação de professores para ministrar a disciplina de Direitos Humanos se faz necessária para que haja um esclarecimento e uma construção de conhecimento que fortaleçam o respeito às diferenças. Somado a essa política de formação docente inicial, sublinhamos a importância da promoção de capacitações que possibilitem o preparo, esclarecimento e aprofundamento teórico e metodológico em relação ao gênero, à sexualidade, à etnia-raça, como campos de produção de saber, imbricados com uma educação para os Direitos Humanos, combatendo o bullying.

Além disso, também é necessário destacar que trabalhar questões de conscientização ao respeito apenas no ambiente escolar não é suficiente para uma transformação social. A escola, a equipe gestora e os docentes não podem assumir a responsabilidade de ser a única instituição capaz de mudar a sociedade. Por isso, devem-se intensificar debates com toda a sociedade, por diferentes meios de comunicação de massa e pesquisas, pois eles são essenciais para atenuar as mazelas que excluem os grupos subalternos no Brasil e fortalecer a luta para edificar uma sociedade mais democrática.

Assim, essa educação cidadã de qualidade se caracteriza como importantíssima na promoção de uma sociedade que valorize o respeito e o aprendizado com as diferenças. Desse modo, a aceitação das múltiplas diferenças, em que os ditos "não normais" vão se "transformando" em cidadãos comuns, vai tomando espaço, promovendo uma sociedade menos excludente. 
Recebido em: 26-02-2018 Aceito em: 09-03-2018

\section{REFERÊNCIAS}

BATISTA, Elise Helena de Morais. Bullying e Preconceitos Étnico-Raciais. In: Revista do Programa de Pós-Graduação em Educação, Florianópolis, V. 7, n. 12, jun/Dez, 2013.

BAUER, Martin W. Análise de Conteúdo Clássica: uma revisão. In: BAUER, Martin W.; GASKELL, George. (Org.). Pesquisa qualitativa com texto, imagem e som: um manual prático. Petrópolis: Vozes, 2010.

BORILLO, Daniel. Homofobia: história e crítica de um preconceito. São Paulo: Autêntica, 2010.

BRASIL. Plano Nacional de Educação (PNE) 2014-2024. Brasília: MEC, 2014.

BRASIL. Lei de Combate às Intimidações Sistemáticas (bullying) $\mathbf{n}^{\mathbf{0}} \mathbf{1 3 . 1 8 5 / 2 0 1 5}$. Brasília: Casa Civil, 2015.

BRASIL. Base Nacional Comum Curricular (BNCC). Brasília: MEC, 2016.

BRUSCHINI, Cristina. "O Trabalho da Mulher no Brasil: Tendências Recentes”. In: SAFFIOTI, Heleieth Iara Bongiovani; MUNÕZ-VARGAS, Mônica (Orgs.). Mulher Brasileira é Assim. Rio de janeiro: Rosa dos Tempos, 1994.

BUTLER, Judith. Problemas de gêneros: feminismo e subversão da identidade. Rio de Janeiro: Civilização Brasileira, 2003.

Cuerpos que Importan: sobre lós limitesmateriales y discursivos del "sexo". Buenos Aires, Barcelona, México: Paidós, 2008.

CANDAU, Vera Maria et all. Educação em Direitos Humanos e a Formação de Professores(as). São Paulo: Cortez, 2013.

CANDAU, Vera Maria; SACAVINO, Susana Beatriz. Educação em Direitos Humanos e Formação de Educadores. In: Revista Educação, Porte Alegre. V. 36, n.1, jan./abr., 2013.

CARRARA, Sérgio e VIANNA, Adriana. "Tá lá o Corpo Estendido no Chão": a violência letal contra travestis no município do Rio de Janeiro. In: Physis, 16, v. 2, 2006.

COSTA, Ricardo Cesar Rocha. O Pensamento Social Brasileiro e a Questão Racial: da ideologia do "branqueamento" às "divisões perigosas". In: (Orgs.) MIRANDA, Claudia; LINS, Mônica R. Ferreira; COSTA, Ricardo Cesar Rocha da. Relações Étnico-Raciais na Escola: desafios teóricos e práticas pedagógicas após a lei n. 10.639. Rio de Janeiro: FAPERJ, 2012.

CRENSHAW, Kimberlé. Documento para o Encontro de Especialistas em Aspectos da Discriminação Racial Relativos ao Gênero. In: Estudos feministas, v. 10, n. 1, 
p. 171, 2002.

DAVIS, Angela. Mulheres, Raça e Classe. São Paulo: Boitempo, 2016.

DIAZ, Gabriela A., SOUZA, Mériti. Bullying Homofóbico: um nome "diferente" para a violência? In: Anais do Fazendo Gênero 9: Diásporas, Diversidade, Deslocamentos, Florianópolis, 2010.

FREIRE, Paulo. Pedagogia da Indignação: cartas pedagógicas e outros escritos. São Paulo: Editora UNESP, 2000.

GARCIA, Marcos R. V. Homofobia e Heterossexismo nas Escolas: discussão da produção científica no Brasil e no mundo. In: Anais da IX ABRAPEE, São Paulo, 2009.

GASKELL, George. Entrevistas Individuais e Grupais. In: BAUER, Martin W.; GASKELL, George. (Org.). Pesquisa qualitativa com texto, imagem e som: um manual prático. Petrópolis: Vozes, 2010.

GOMES, Nilma Lino. Educação, Raça e Gênero: relações imersas na alteridade. In: Cadernos Pagu (6-7), Campinas 1996.

Movimento Negro e Educação: ressignificando e politizando a raça. In: Educação e Sociedade, Campinas, v. 33, n. 120, jul.-set. 2012

LOURO, Guacira Lopes. Gênero, Sexualidade e Educação: Uma perspectiva pósestruturalista. Petrópoles: Vozes, 1997.

LÜDKE, Menga; ANDRÉ, Marli E. D. A. Pesquisa em Educação: abordagens qualitativas. Rio de Janeiro: E.P.U, 2014.

MATTOS, Patrícia. O Conceito de Interseccionalidade e suas Vantagens para os Estudos de Gênero no Brasil. In: Anais XV SBS, 2011.

MESSIAS, Elizama Pereira. A Implantação das Políticas Educacionais de Promoção da Igualdade Racial na Cidade do Recife. (Orgs.) SANTIAGO, Eliete; SILVA, Delma; SILVA, Claudilene. In: Educação, Escolarização e Identidade Negra: 10 anos de pesquisa sobre relações raciais no PPGE/UFPE. Recife: Editora Universitária UFPE, 2010.

MIRANDA, Marcelo H. Gonçalves de. Condensação de Sentidos e Paródia: categorização social sobre sexo, gênero e sexualidade. 2013. Tese (Doutorado em Sociologia) - Programa de Pós-Graduação em Sociologia, Universidade Federal de Pernambuco, Recife.

Magistério Masculino: (re)despertar tardio da docência. Recife: Editora Universitária da UFPE, 2011.

MISKOLCI, Richard. Teoria Queer: um aprendizado pelas diferenças. Belo Horizonte: Autêntica, 2012.

Um Corpo Estranho na Sala de Aula. (Orgs.) ABRAMOWICZ, Anete; SILVÉRIO, Valter Roberto. In: Afirmando Diferenças: montando o quebra-cabeça da 
diversidade na escola. São Paulo: Papirus, 2010.

OLIVEIRA, Luiz Fernandes de. "A Sala de Aula é o Último Lugar Onde Ocorrerão Mudanças". Lei 11.465: suas implicações teóricas e práticas na recente produção acadêmica. In: (Orgs.) MIRANDA, Claudia; LINS, Mônica R. Ferreira; COSTA, Ricardo Cesar Rocha da. Relações Étnico-Raciais na Escola: desafios teóricos e práticas pedagógicas após a lei n. 10.639. Rio de Janeiro: FAPERJ, 2012.

PERLONGHER, Nestór Osvaldo. O Negócio do Michê: prostituição viril em São Paulo. São Paulo: Brasiliense, 1987.

PERNAMBUCO. Plano Estadual de Educação de Pernambuco 2015-2025. Recife: Secretaria de Educação, 2015

PRADO, Marco Aurélio Máximo e JUNQUEIRA, Rogério Diniz. Homofobia, Hierarquização e Humilhação Social. In: VENTURI, Gustavo; BOKANY, Vilma (Orgs.) Diversidade Sexual e homofobia no Brasil. São Paulo, Fundação Perseu Abramo, 2011.

PISCITELLI, Adriana. Interseccionalidades, Categorias de Articulação e Experiências de Migrantes Brasileiras. In: Sociedade e Cultura, v.11, n.2, jul/dez. 2008.

RAMIRES, Luis. Homofobia na escola: o olhar de um educador social do movimento LGBT. In VENTURI, Gustavo e BOKANY, Vilma (Orgs.). Diversidade Sexual e Homofobia no Brasil. São Paulo: Perseu Abramo, 2011.

RODINO, Ana María. Qué Revelan las Investigaciones sobre las Actuales Prácticas Pedagógicas y Didáticas de Educación en Derechos Humanos en América Latina. In: XVI ENDIPE - Encontro Nacional de Didáticas e Práticas de Ensino. Campinas: UNICAMP, 2012.

SAFFIOTI, Heleieth Iara Bongiovani. O Poder do Macho. São Paulo: Moderna, 1996

SCOTT, Joan Wallach. Gênero: uma categoria útil para a análise histórica. Recife: SOS Corpo, 1996.

Experiência. In: SILVA, Alcione Leite da; LAGO, Mara Coelho de Souza; RAMOS, Tânia R. Oliveira. (Orgs.) Falas de Gênero. Florianópolis, Ed. Mulheres, 1999.

SILVA, JOILSON P. da., BARRETO, Nayana S. Violência Escolar: problematizando a relação entre o bullying e a homofobia. In: Revista Fórum Identidades, Itabaiana: GEPIADDE, V. 12, jul/dez, 2012.

SILVA, Joyce M. A. de P., SALLES, Leila M. F. A Violência na escola: abordagens teóricas e propostas de prevenção. In: Educar em Revista, Curitiba, n. especial 2, 2010.

STOLKE, Verena. O Enigma das Interseções: classe," raça", sexo", sexualidade. A formação dos impérios transatlânticos do século XVI ao XIX. In: Estudos Feministas, v. 14, n. 1, p. 15-42, 2006. 
VENTURI, Gustavo; BOKANY, Vilma. (Orgs.) Diversidade Sexual e Homofobia no Brasil. São Paulo: Fundação Perseu Abramo, 2011. 